This is the peer reviewed version of the following article: [Mills, D.J., Milyavskaya, M., Mettler, J., Heath, N.L., and Derevensky, J.L. (2018). How do passion for video games and needs frustration explain time spent gaming? British Journal of Social Psychology, 57(2), 461-481. doi:10.1111/bjso.12239.

\title{
How do passion for video games and needs frustration explain time spent gaming?
}

Research applying self-determination theory and the dualistic model of passion (DMP)

has shown video games may satisfy basic psychological needs (i.e., competence, autonomy, and relatedness) and be identified as a passion. The DMP distinguishes between healthy or harmonious passion and problematic or obsessive passion (OP), with the latter reflecting an overreliance towards one's passion to obtain needs satisfaction. The experience of daily obstructions to needs satisfaction, or needs frustration (NF), may facilitate such an overreliance. This study explored how NF and both types of passion explain the amount of time that university students spend gaming. The overall association between NF and time spent gaming was not significant. However, for video game users with low levels of OP for gaming, there was a significant negative association between NF and time spent gaming. Additionally, evidence of a mutually reinforcing association between NF and OP for gaming indicates that a vicious cycle exists, whereby a strong OP for gaming predicts and is reinforced by greater NF. The theoretical implications are discussed.

The word passion portrays a sense of significance that is often attributed to an activity or a cause. The dualistic model of passion (DMP) defines a passion as a meaningful, self- defining activity (Vallerand, 2010, 2015; Vallerand et al., 2003). Drawing upon self- determination theory (Ryan \& Deci, 2000, 2017), DMP proposes the continued satisfaction of three basic psychological needs during activity engagement, namely individuals' sense of competence, autonomy, and relatedness, facilitates passion development. Critically, the model distinguishes between a healthy or harmonious passion (HP) and a problematic or obsessive passion (OP). Recent research suggests the differences between these two types of passion stem in part from an imbalance in daily needs satisfaction, such that OP individuals are overly reliant upon their 
passions to meet their basic needs (Lalande et al., 2017). In this regard, the prolonged experience of needs frustration, which implies the frequent occurrence of obstacles thwarting the satisfaction of basic psychological needs, might contribute to greater engagement in one's passion as well as facilitate a sense of dependence towards the activity (Vansteenkiste \& Ryan, 2013). Within the context of video games, the present investigation assesses the extent to which fluctuations in daily needs frustration contribute to time spent gaming, and whether the association between needs frustration and time spent gaming depends on reports of either a HP or OP for gaming. Additionally, the existence of a mutually reinforcing association between either needs frustration and time spent gaming with HP and OP for gaming is explored.

Vallerand et al. (2003) suggest individuals, regardless of the type of passion they possess, love and are invested in their passion. As a result, HP and OP are conceptually similar at a foundational level. However, research has consistently demonstrated that HP is positively associated with adaptive outcomes, whereas OP is positively associated with maladaptive outcomes (see large meta-analysis by Curran, Hill, Appleton, Vallerand, \& Standage, 2015). Although greater detail is provided by Vallerand (2010, 2015), theory suggests the different outcomes associated with either HP or OP originate from disparities in how HP and OP are internalized within the self. HP is internalized autonomously, implying individuals maintain control over engagement in their passion, and thus experience low conflict between their desire to engage in their passion and other personal and social responsibilities. On the other hand, OP represents a controlled internalization, implying the activity maintains control over individuals, and thus is prioritized over other responsibilities. As a result, research has found HP to affect other life domains positively (Luth, Flinchbaugh, \& Ross, 2017; Stenseng \& Phelps, 2013) as well as to be associated with greater life satisfaction (Lafreni'ere, Vallerand, \& Sedikides, 2013), 
This is the peer reviewed version of the following article: [Mills, D.J., Milyavskaya, M., Mettler, J., Heath, N.L., and Derevensky, J.L. (2018). How do passion for video games and needs frustration explain time spent gaming? British Journal of Social Psychology, 57(2), 461-481. doi:10.1111/bjso.12239.

higher intimacy with romantic partners (Ratelle, Carbonneau, Vallerand, \& Mageau, 2013), and healthier psychological adjustment during retirement (Houlfort et al., 2015). Similar studies have found OP to be associated with greater burnout (Carbonneau, Vallerand, Fernet, \& Guay, 2008; Donahue et al., 2012), weaker global self-esteem (Stenseng \& Dalskau, 2010), poorer interpersonal relationships (Vallerand et al., 2008), and greater aggression towards another team and their fans (Bureau, Vallerand, Ntoumanis, \& Lafreni'ere, 2012; Donahue, Rip, \& Vallerand, 2009; Vallerand et al., 2008). To date, only two prospective studies have explored the developmental determinants of HP and OP. Mageau et al. (2009) found greater autonomous support from key authority figures (e.g., coaches, teachers, parents) positively contributed to the development of HP. In line with believed differences in how HP and OP are internalized, this finding suggests feeling less coercion to participate in their passion is an important to the development of HP. Another study by Lalande et al. (2017) found less needs satisfaction across life domains (e.g., work, school, relationships) contributed to the reports of OP. In the authors' words, this finding is evidence that OP is a compensatory response to a lack of daily needs satisfaction. Therefore, individuals are controlled by the desire to satisfy their needs through engagement in their passion. Vansteenkiste and Ryan (2013) argue that consideration of deficits in needs satisfaction is not as important as the extent to which individuals are experiencing impediments or obstructions to satisfying these basic psychological needs.

For more than a decade, the frustration or thwarting of basic psychological needs, henceforth referred to as needs frustration, has been proposed to be essential in understanding issues related to ill-being as well as the development of psychopathologies (Deci \& Ryan, 2000; Ryan, Deci, Grolnick, \& La Guardia, 2006; Ryan, Deci, \& Vansteenkiste, 2016). However, it has 
only recently been studied within the self- determination theory literature as a construct separate from low needs satisfaction (Bartholomew, Ntoumanis, Ryan, Bosch, \& Thøgersen-Ntoumani, 2011; Chen et al., 2015; Costa, Ntoumanis, \& Bartholomew, 2015). This emerging research has shown that beyond a lack of needs satisfaction, the experience of greater needs frustration is linked strongly to reports of depressive symptoms and negative affect (Chen et al., 2015; Gunnell, Crocker, Wilson, Mack, \& Zumbo, 2013). Although low needs satisfaction will always accompany needs frustration, it is possible that low needs satisfaction may also occur without the presence of active impediments, inferring there is no experience of needs frustration (Vansteenkiste \& Ryan, 2013). Importantly, needs frustration is an environmental factor that has not yet been assessed in conjunction with reports of either passion type. In line with the Lalande et al. (2017) findings, stronger OP is expected to correlate with greater needs frustration. However, building on this area of research, a further question is whether needs frustration actually contributes to a change in the frequency of engaging in an activity presumed to satisfy basic needs, and whether or not this association depends on possessing either a HP or OP towards the activity.

Research has shown that playing video games has the potential to satisfy the three basic psychological needs and that these needs play an essential role in promoting more frequent gameplay and overall gaming enjoyment (Johnson, Gardner, \& Sweetser, 2016; Peng, Lin, Pfeiffer, \& Winn, 2012; Ryan, Rigby, \& Przybylski, 2006; Tamborini, Bowman, Eden, Grizzard, \& Organ, 2010). As a result, individuals may additionally form a passion towards gaming. Moreover, a great deal of research has attempted to better understand a problematic style of engagement in video games, often referred to as Internet Gaming Disorder (Griffiths et al., 2016; King, Haagsma, Delfabbro, Gradisar, \& Griffiths, 2013; Przybylski, Weinstein, \& Murayama, 
This is the peer reviewed version of the following article: [Mills, D.J., Milyavskaya, M., Mettler, J., Heath, N.L., and Derevensky, J.L. (2018). How do passion for video games and needs frustration explain time spent gaming? British Journal of Social Psychology, 57(2), 461-481. doi:10.1111/bjso.12239.

2017). Previous research has shown OP for gaming is strongly correlated with reports of

Internet Gaming Disorder symptoms (Lafreni'ere, Vallerand, Donahue, \& Lavigne, 2009;

Wang \& Chu, 2007); therefore, application of both needs frustration and DMP to the area of video game engagement may inform the tangentially related area of Internet Gaming Disorder.

This study addresses two key gaps within the existing literature corresponding to two separate objectives. The first objective addressed the association between needs frustration and time spent gaming, and the roles of HP and OP for gaming in moderating this association. It is hypothesized that greater needs frustration will be associated with greater time spent gaming. This is expected in part due to the potential of satisfying basic needs through playing video games, as observed by previous research. Further, in line with Lalande et al. (2017) description of OP as a compensatory response to a deficit in needs satisfaction, it is hypothesized that OP for gaming will positively moderate the association between daily needs frustration and time spent gaming such that greater daily needs frustration will be associated with greater time spent gaming for those reporting a stronger OP for gaming. The role of HP for gaming as a moderator is less clear. As a result, no hypothesis can be made for the role of HP for gaming as moderating the association between needs frustration and time spent gaming.

Gender is additionally hypothesized to moderate the association between daily needs frustration and time spent gaming. Previous research has revealed that males tend to report spending more time gaming than females (Lemmens, Valkenburg, \& Gentile, 2015; Rehbein, Kleimann, \& Mo€ssle, 2010). Moreover, females tend to not internalize a gamer identity (Shaw, 2012), which suggests that females may not generally view video games as an activity that satisfies their basic needs. Thus, a stronger and positive association between daily needs frustration and time spent gaming is expected for males compared to females. 
The second objective addresses the extent to which a mutually reinforcing association exists for time spent gaming and daily needs frustration with either a HP or OP for gaming over time. It is hypothesized that OP for gaming would be predictive of greater needs frustration and time spent gaming, but only an increase in needs frustration is expected to positively reinforce individuals' OP for gaming. This hypothesis draws upon the theoretical and empirical support demonstrating that various environmental factors such as the roles needs satisfaction and autonomy support play in contributing to the development of either a dominant HP or OP (Lalande et al., 2017; Mageau et al., 2009). No hypothesis was made regarding the possibility of such an association with HP for gaming given the lack of evidence supporting the presence of an association.

\section{Methods}

\section{Participants}

Two cohorts were recruited during the 2015-2016 academic year. The first cohort was recruited during the Fall Term and the second cohort during the Winter Term, henceforth referred to as the Fall Cohort and Winter Cohort, respectively. Across both cohorts, 752 participants (Fall Cohort: $n=349$; Winter Cohort: $n=403$ ) completed online questionnaires at the initial or Baseline wave of the study. As shown in Figure 1, five steps were taken in selecting a final sample within each cohort. Gender and age differences between those included and those excluded were assessed whenever possible with the results of these comparisons included as notes to Figure 1. Importantly, about a third of each cohort did not provide their contact information resulting in their exclusion. This is a common problem with online data where anonymity is strongly desired. Nonetheless, those who were excluded were not significantly different from those included in the study. The final sample includes 147 participants in the Fall 
This is the peer reviewed version of the following article: [Mills, D.J., Milyavskaya, M., Mettler, J., Heath, N.L., and Derevensky, J.L. (2018). How do passion for video games and needs frustration explain time spent gaming? British Journal of Social Psychology, 57(2), 461-481. doi:10.1111/bjso.12239.

Cohort and 143 participants in the Winter Cohort. Demographics of each cohort at Baseline are presented in Table 1.

\section{Measures}

\section{Demographic variables}

Participants reported their gender (male, female), age, and if (Yes/No) they were enrolled in a graduate programme. Time spent gaming was measured by participants' estimation of the number of hours they spent playing video games in the past week.

\section{Needs frustration}

An adapted version of Psychological Need Thwarting Scale (PNTS; Bartholomew, Ntoumanis, Ryan, \& Thøgersen-Ntoumani, 2011) was used to assess the general experience of needs frustration. Originally developed to assess needs frustration in an athletic activity, items were changed to address more general experiences across life domains. For example, the original item, 'In my sport, I feel forced to follow training decisions made for me', was changed to, 'I feel forced to follow decisions made for me'. Additionally, participants were asked to reflect upon the past week while rating the frequency they experienced each item from (1) almost never to (6) almost always. Greater scores indicated greater needs frustration. Two previous studies using this adapted version of the PNTS have shown an item from the relatedness frustration subscale, 'I feel that other people are envious when I achieve success', and an item from the competence frustration subscale, 'I feel inadequate because I am not given opportunities to fulfill my potential', consistently loaded poorly on their respective factors (Mills, Milyavskaya, Derevensky, \& Heath, in press; Mills, Milyavskaya, Mettler, \& Heath, 2017). Therefore, both items were excluded resulting in two 3-item subscales for competence and relatedness frustration and one 4-item subscale for autonomy frustration. The internal consistencies are presented in 
Table 3. Within this study, an average of all ten items was used as a composite measure of daily needs frustration.

\section{Passion scale}

Participants completed an adapted version of Vallerand's (2010) Passion Scale, which includes two 6-item subscales that assess participants' HP and OP towards an activity they identify. Items were changed to directly assess participants' HP and OP for gaming. For instance, the item 'This activity reflects the qualities I like about myself' was changed to 'My video game use reflects qualities I like about myself'. Each of the items was rated on a 7- point scale ranging from (1) not at all agree to (7) very strongly agree. The averages of each subscale were used as indication of participants' harmonious and obsessive passion for gaming. The internal consistencies are presented in Table 3.

\section{Procedure}

This study consisted of two parts. An online questionnaire was completed using the LimeSurvey software in each part of the study. The first part of the study was Baseline. At this stage, individuals were recruited using an existing database of university student emails as well as flyers posted throughout a large university campus. The Baseline questionnaire included items assessing basic demographic variables (e.g., age, gender) and passion for gaming as well as time spent gaming and experiences of needs frustration during the past week. Baseline began in September 2015 for the Fall Cohort and January 2016 for the Winter Cohort. Both concluded approximately 1 month later. Participating at Baseline as well as providing personal information (e.g., phone, email) resulted in being entered in a raffle for one of four Amazon gift cards. This raffle took place after the first part of the study.

The second part of the study began approximately 2 weeks after the conclusion of 
This is the peer reviewed version of the following article: [Mills, D.J., Milyavskaya, M., Mettler, J., Heath, N.L., and Derevensky, J.L. (2018). How do passion for video games and needs frustration explain time spent gaming? British Journal of Social Psychology, 57(2), 461-481. doi:10.1111/bjso.12239.

Baseline. Participants who had provided personal information at Baseline were invited via email to participate in a series of five follow-up waves every 2 weeks. Each follow-up questionnaire included items assessing time spent gaming and experiences of needs frustration for the past week as well as several other items not associated with any of the hypotheses in this study. A raffle for Amazon gift cards was used as an incentive for participation in the second part of the study; however, each completed follow-up wave questionnaire resulted in one entry in the raffle. As a result, participants were told that completing all waves would increase their chances of winning an Amazon gift card at the end of the study. The average number of days between Baseline and the Final Wave was 75.87 ( $S D=8.08$ days). Wave 2 was found to be on average 33.90 days $(S D=8.39$ days $)$ after Baseline, and 42.35 days ( 1.97 days $)$ before the Final Wave making it an approximate mid-point in the study.

\section{Analytic strategy}

Prior to conducting the primary analyses, differences at Baseline between the Fall Cohort and Winter Cohort were explored using both chi-square tests and t-tests. Differences at Baseline were also assessed between those enrolled in graduate and undergraduate programmes using similar tests. The pattern of missingness across the entire study was assessed using Little's (1988) missing complete at random (MCAR) test. SPSS version 22 was used to conduct these analyses.

The first objective explored the association between daily needs frustration and time spent gaming, and the roles of HP and OP for gaming and gender in moderating this association. Given the nested nature of the data, multilevel modelling with random intercepts and random slopes was used as the primary analysis (Muth'en \& Muth'en, 2015). An advantage of this analysis is the ability to assess the variability of the association between daily needs frustration 
and time spent gaming at the within level, and assess whether individual differences at the between level (i.e., HP, OP, gender) account for the observed variability. This analysis was conducted using $M_{\text {plus version }} 7.4$ (Muth'en \& Muth'en; Los Angeles, CA, USA).

The second objective was to assess the existence of a mutually reinforcing association for time spent gaming and needs frustration with either a HP or OP for gaming. As recommended by Cole and Maxwell (2003), a cross-lagged analysis with autoregressive path coefficients was performed on data from Baseline, the Final Wave, and Wave 2, given its approximate placement as a mid-point in this study. Structural equation modelling was used to calculate fit indices. For this study, values of .08 or lower for root mean square error of approximation (RMSEA), near or above .95 for both comparative fit index (CFI) and Tucker-Lewis Index (TLI), and less than .06 for standardized root mean-squared residual (SRMR) were used to indicate acceptable fit (Byrne, 2013; Hu \& Bentler, 1999; Kline, 2016). This analysis was also conducted using $\mathrm{M}_{\text {plus }}$ version 7.4 (Muth'en \& Muth'en).

\section{Results}

\section{Preliminary analyses}

A series of analyses were conducted to assess differences between the Fall Cohort and Winter Cohort using data collected at Baseline. The averages for each cohort are shown in Table 1 with statistical analyses provided in the final column. The Winter Cohort was slightly older $(d$ $=.32)$ and reported greater OP for gaming $(d=.29)$ compared to the Fall Cohort. Moreover, the Winter Cohort also reported greater time spent gaming at Baseline than the Fall Cohort $(d=.40)$. There were no differences in the proportion of males and females or university students enrolled in undergraduate or graduate programmes between both cohorts. Furthermore, the two cohorts did not significantly differ in reports of HP for gaming or experiences of needs frustration at 
This is the peer reviewed version of the following article: [Mills, D.J., Milyavskaya, M., Mettler, J., Heath, N.L., and Derevensky, J.L. (2018). How do passion for video games and needs frustration explain time spent gaming? British Journal of Social Psychology, 57(2), 461-481. doi:10.1111/bjso.12239.

Baseline. Therefore, although some differences between the two cohorts were identified, these differences were relatively small with reference to Cohen's (1988) d, indicating a possibility of collapsing the two cohorts into one sample.

Prior to collapsing the two cohorts into one sample, pattern of missingness across the entire study was assessed within each cohort using Little's (1988) MCAR test. If missing data can be reliably estimated for both cohorts, then the two cohorts may be combined into one sample. Either a nonsignificant chi-square test or a $\chi^{2} / d f$ ratio value less than 2 suggests missing values can be estimated reliably (Bollen, 1989). The $\chi^{2} / d f$ ratio values for the Fall Cohort and Winter Cohort were both under 2 (Fall Cohort: 631.61/344 = 1.84; Winter Cohort: 555.74/325 = 1.71), suggesting missing values for both cohorts could be estimated reliably. Therefore, the two cohorts were combined into one larger sample. Little's (1988) MCAR test was conducted once more for the entire sample. Results reveal a $\chi^{2} / d f$ ratio value less than $2(919.80 / 495=1.86)$. Thus, the criterion of MCAR was met, and full-information maximum likelihood was used to estimate missing values for the primary analyses.

A final issue was the potential for differences to exist between those enrolled in undergraduate versus graduate programmes. Table 2 presents averages for Baseline data with statistical analyses provided in the final column. Not surprisingly, participants enrolled in a graduate programme were older $(d=1.21)$. However, no other differences were observed between those enrolled in undergraduate versus graduate programmes at Baseline. Therefore, both undergraduate and graduate university students were included in the primary analyses.

\section{Primary analyses}

Correlations as well as means and standard deviations for HP for gaming, OP for gaming, time spent gaming, and needs frustration were calculated for each wave of study (see Table 3). 
Given the number of comparisons, a Bonferroni correction was used to calculate a modified pvalue $(p<.0004)$, which was subsequently used to assess for significance of the observed correlation values. Reports of HP and OP for gaming, time spent gaming, and experiences of needs frustration were relatively stable across the entire study. In addition to bivariate correlations, intraclass correlations were calculated providing further support of the overall reliability of HP for gaming (ICC $=.83$ ), OP for gaming $(\mathrm{ICC}=.75)$, time spent gaming $(\mathrm{ICC}=$ .93 ), and daily needs frustration (ICC $=.94)$ over the duration of the study. Beyond an assessment of stability, the bivariate correlations demonstrated that compared to females, males reported a significantly stronger OP for gaming at Baseline as well as greater time spent gaming at each wave of the study. Finally, the association between needs frustration and time spent gaming was not found to be significant within any wave of the study. Although the lack of statistical significance does not support the hypothesized association between needs frustration and time spent gaming, this finding does not invalidate the possibility that individual differences (i.e., HP for gaming, OP for gaming, and gender) may moderate the association between needs frustration and time spent gaming.

The first objective was to assess the association between daily needs frustration and time spent gaming, and the role of individual differences (i.e., HP for gaming, OP for gaming, gender) in moderating the association. Muth'en and Muth'en's (2015) instructions for a two-level multilevel model analysis were followed. Data from all six waves of the study were clustered by participants' unique identification numbers, and models were created at both the within and between levels. At the within level, daily needs frustration was included as a latent variable with averages for competence, autonomy, and relatedness frustration used as indicators. Time spent gaming was regressed onto reports of daily needs frustration. To account for the wave-to-wave 
This is the peer reviewed version of the following article: [Mills, D.J., Milyavskaya, M., Mettler, J., Heath, N.L., and Derevensky, J.L. (2018). How do passion for video games and needs frustration explain time spent gaming? British Journal of Social Psychology, 57(2), 461-481. doi:10.1111/bjso.12239.

stability of both needs frustration and time spent gaming, two additional paths were included to allow reports of needs frustration and time spent gaming from the previous wave to predict daily needs frustration and time spent gaming, respectively. At the between level, individual differences from Baseline (HP for gaming, OP for gaming, gender) were set to predict the intercepts of time spent gaming and daily needs frustration as well the slope of the association between daily needs frustration and time spent gaming from the within level of the model. A significant association between individual differences from Baseline and the slope of the association would indicate a moderation effect.

Consistent with the correlations presented in Table 3, needs frustration was not significantly associated with time spent gaming (see top panel of Figure 2). Results from the between-level analysis (see bottom panel of Figure 2) indicated that both HP for gaming and OP for gaming at Baseline were positively associated with time spent gaming intercepts. Gender was negatively associated with the time spent gaming intercept, indicating males reported spending more time playing video games than females. As hypothesized, OP for gaming was positively associated with the intercept of daily needs frustration $(\beta=.22, p=.01,95 \mathrm{CI}[0.06,0.38])$, indicating that higher OP for gaming was generally associated with greater needs frustration throughout the study. On the other hand, HP for gaming was negatively associated with the daily needs frustration intercept, demonstrating that higher HP for gaming was generally associated with lower needs frustration throughout the study $(\beta=.21, p=.02,95 \mathrm{CI}[0.38,0.03])$. Daily needs frustration intercepts did not significantly differ between males and females.

Finally, the moderation effects of HP for gaming, OP for gaming, and gender on the association between needs frustration and time spent gaming were assessed. It was found that OP for gaming at Baseline was positively associated with the slope of the association between needs frustration 
and time spent gaming $(\beta=.25, p=.01,95 \mathrm{CI}[0.06,0.45])$, supporting the hypothesis that OP for gaming moderates the association between needs frustration and time spent gaming. A review of the interaction (see Figure 3a), however, did not support the expectation that needs frustration would be more strongly related to time spent gaming for participants who reported a greater OP for gaming. Rather, simple- slopes analyses, as described by Preacher, Curran, and Bauer (2006) for multilevel models, suggest the association was not significant for high-OP (+1 SD) participants $(\beta=.03, p=.36,95 \mathrm{CI}[0.09,0.03])$, but was significant for low-OP for gaming ( 1 SD) participants $(\beta=.11, p=.002,95 \mathrm{CI}[0.17,0.05])$. Moreover, the direction of the association for low-OP for gaming participants was negative, indicating that greater needs frustration was associated with less time spent gaming. HP for gaming was not found to be significantly related to the slope of the association between needs frustration and time spent gaming.

Gender was also found to moderate the association between needs frustration and time spent gaming $(\beta=.25, p=.001,95 \mathrm{CI}[0.11,0.40])$. A review of interaction (see Figure $3 b)$ did not support the expected linear relation between needs frustration and time spent gaming. Once again, simple-slopes analyses were conducted for a multilevel model. The results revealed a significant negative association between needs frustration and time spent gaming for males $(\beta=$ $10, p=.006,95$ CI [ $0.16,0.04])$, but not for females $(\beta=.04, p=.23,95$ CI [ $0.03,0.11])$. Moreover, the association for males was negative, thus contradicting the expected positive association.

The second objective was to assess the existence of a mutually reinforcing association for time spent gaming and daily needs frustration with either a HP for gaming or OP for gaming. Figure 4 presents the hypothesized model. Once again, needs frustration was included as a latent 
This is the peer reviewed version of the following article: [Mills, D.J., Milyavskaya, M., Mettler, J., Heath, N.L., and Derevensky, J.L. (2018). How do passion for video games and needs frustration explain time spent gaming? British Journal of Social Psychology, 57(2), 461-481. doi:10.1111/bjso.12239.

variable at Baseline, Wave 2, and Final Wave with averages for competence, autonomy, and relatedness frustration used as indicators at each wave. The error terms of each need were correlated with the error terms of the respective need at each wave. For instance, the error term of competence frustration at Baseline was correlated with the error terms of competence frustration at Wave 2 and at Final Wave. Averages of HP for gaming and OP for gaming and estimates of time spent gaming were entered as observed variables. Gender was included as a covariate within the model. The initial results of this model revealed less than adequate fit, $\chi^{2}(82)=213.30, p=.001 ;$ RMSEA $=.07$, 90CI $[0.06,0.09] ;$ CFI $=.92 ;$ TLI $=.87 ;$ SRMR $=$ .08. A review of the modification indices suggested fit could be substantially improved by allowing the error terms of OP for gaming at Baseline to correlate with the error terms of both time spent gaming at Baseline and needs frustration at Baseline. Fit indices were recalculated with evidence of good fit, $\chi^{2}(80)=120.22, p=.002$; $\mathrm{RMSEA}=.04,90 \mathrm{CI}[0.03,0.06]$; CFI $=$ $.98 ; \mathrm{TLI}=.96 ; \mathrm{SRMR}=.05$.

Figure presents the path coefficients observed in the cross-lagged analysis. As expected, the results show HP for gaming and OP for gaming to be relatively stable over the course of one academic term (HP to HP: $\beta=.65, p<.001,95 \mathrm{CI}[0.56,0.74]$; OP to OP: $\beta=.33, p<.001,95$ CI $[0.17,0.49])$. Similarly, needs frustration and time spent gaming were found to be quite stable. In line with expectations, OP for gaming at Baseline was significantly associated with reports of needs frustration at Wave $2(\beta=.18, p=.01,95 \mathrm{CI}[0.04,0.32]$, which in turn was significantly associated with OP for gaming at Final Wave $(\beta=.29, p<.001,95$ CI [0.17, 0.42]). An assessment of the indirect effect of OP for gaming at Baseline onto OP for gaming at Final Wave through reports of needs frustration at Wave 2 indicated a significant mediation $(\beta=.05, p$ $=.04,95 \mathrm{CI}[0.01,0.10])$, thus supporting the existence of a mutually reinforcing association 
between OP for gaming and needs frustration. The indirect effect for time spent gaming was not significant. HP at Baseline was not significantly associated with needs frustration at Wave 2, and neither HP or OP at Baseline was associated with time spent gaming at Wave 2.

\section{Discussion}

Within the context of video game engagement, the present study applied the emerging construct of needs frustration to the dualistic model of passion (Vallerand, 2010, 2015; Vallerand et al., 2003) to better understand time spent gaming. Previous research demonstrates that playing video games can potentially satisfy the three basic psychological needs (competence, autonomy, and relatedness; Peng et al., 2012; Ryan, Deci, et al., 2006; Ryan, Rigby, et al., 2006; Tamborini et al., 2010). Therefore, it was hypothesized that greater daily needs frustration would be associated with greater frequency playing video games. However, it was further expected that individuals' HP and OP for gaming as well as the underlying gender differences in video game engagement might affect the relationship between needs frustration and time spent gaming. Additionally, it was hypothesized that a mutually reinforcing association would exist between an OP for gaming and reports of daily needs frustration. Although support for the positive association between needs frustration and time spent gaming was not found within the present study, the present results did reveal a moderation effect of OP for gaming. Specifically, OP moderated the association between needs frustration and time spent gaming. We also found a mutually reinforcing association between OP for gaming and daily needs frustration. These results have theoretical implications for understanding individuals' gaming patterns as well as variables potentially contributing to a more problematic style of gaming engagement. Consistent with previous studies, males reported greater time spent gaming than females, and both HP for gaming and OP for gaming were positively associated with time spent gaming 
This is the peer reviewed version of the following article: [Mills, D.J., Milyavskaya, M., Mettler, J., Heath, N.L., and Derevensky, J.L. (2018). How do passion for video games and needs frustration explain time spent gaming? British Journal of Social Psychology, 57(2), 461-481. doi:10.1111/bjso.12239.

(Johnson et al., 2016; Przybylski, Weinstein, Ryan, \& Rigby, 2009; Wang \& Chu, 2007).

However, this is the first study, to the authors' knowledge, showing a gender difference in OP for any activity, with males reporting greater OP for gaming than females. Only one study to date has previously assessed for gender differences in HP and OP for gaming and reported that this difference was not significant, possibly due to the high proportion (87\%) of male participants (Lafreni'ere et al., 2009). The gender difference in HP did not reach significance in the present study; however, it should be noted that this is due to the required modification to the alpha given the number of comparisons conducted.

Although these associations and gender differences were of interest, the first objective of the present study addressed the association between needs frustration and time spent gaming, and the role of HP for gaming, OP for gaming, and gender in moderating the association. It was hypothesized that needs frustration would be positively associated with time spent gaming for two reasons. First, video games are commonly reported to be used as mood management strategy (Fuster et al., 2012; Reinecke, 2009; Yee, 2006). Second, the frustration of basic needs and their later satisfaction through gaming has been used in a recent experimental study to explain mood management through gaming (Reinecke et al., 2012). Therefore, to alleviate the negative feelings brought upon by needs frustration, individuals were expected to report greater time spent gaming presumably as a means for satisfying their basic needs, and thus, increasing their overall wellbeing. As already mentioned, the present data did not support this association. It is possible that the limited time between each wave of data collection did not allow for substantial changes in the experiences of needs frustration nor gaming patterns. Moreover, increasing the time between wave points could allow for changes in personal and social responsibilities, which may likely contribute in some way to the experience of needs frustration as well as general gaming patterns. 
Nonetheless, the correlation coefficient for the association between needs frustration and time spent gaming was around zero across each wave of the study.

The present findings did support the role of OP and gender in moderating the association between needs frustration and time spent gaming; however, in both cases, the exact function of the moderation did not work as expected. First, greater OP for gaming was expected to predict a stronger, positive association between needs frustration and time spent gaming in support of Lalande et al. (2017) claim that OP (more generally) is a compensatory response to a deficit of needs satisfaction. As a result, it was expected that when needs are frustrated, OP video game users would play video games more frequently to compensate for the lack of needs satisfaction in their daily life. Instead, our results indicated the association between needs frustration and time spent gaming was not significant for high-OP video game users, but was significant for low-OP video game users. Moreover, the observed association for low-OP video game users was negative, indicating that as needs frustration rose time spent gaming decreased. Although contrary to our hypothesis, these results are of interest as they suggest high-OP video game users do not modify their gaming pattern with the experience of needs frustration. In fact, their pattern of engagement was found to be quite stable. Yet, low-OP video game users will decrease, albeit minimally, their time spent gaming possibly as a means of dealing with their experiences of needs frustration. For instance, perceiving threats to a sense of competence in university or a sense of relatedness within an intimate relationship might provoke the desire to prioritize more time towards these important areas by spending more time studying or with one's partner. Unlike those with low-OP for gaming, high-OP video game users may be unable to change his or her pattern of video game engagement to address these threats. Rather, they may retreat within the gaming world possibly due to an overly developed 'preference toward a virtual life' (Liu \& 
This is the peer reviewed version of the following article: [Mills, D.J., Milyavskaya, M., Mettler, J., Heath, N.L., and Derevensky, J.L. (2018). How do passion for video games and needs frustration explain time spent gaming? British Journal of Social Psychology, 57(2), 461-481. doi:10.1111/bjso.12239.

Peng, 2009). Therefore, this finding speaks to the ability of low-OP video game users compared to high-OP video game users to manage and further modify their video game use. Further research is needed to address more directly whether the control underlying OP is indeed related to the role video gaming engagement plays in satisfying individuals' basic needs relative to other areas of one's life as it has been proposed in theory.

Second, it was expected that gender would moderate the association between needs frustration and time spent gaming such that the association would be stronger for males compared to females, and in a positive direction. The results supported the role of gender in moderating the association as well as the expectation that the association would be stronger for males than females; however, the association was once again negative. Thus, for males, greater needs frustration was associated with less time spent gaming, whereas for females, greater needs frustration was not significantly associated with time spent gaming. The negative association was unexpected, as males tend to report greater time spent gaming as well as endorse more symptoms of problematic gaming (Lemmens et al., 2015; Rehbein et al., 2010), which Lafreni'ere et al. (2009) found to be correlated strongly with OP for gaming. This finding likely points towards an overall gender difference in time spent gaming; that is, the greater quantity of video game engagement reported by males than females created an artificially more dramatic decrease in time spent gaming in response to daily needs frustration. Therefore, it is not believed that this finding indicates males to be more likely to reduce their time spent gaming in response to needs frustration, rather, given that they already play less frequently on average, females do not need to reduce their time spent gaming as much as males do in response to needs frustration.

The second objective of the present study was to assess the hypothesized mutually reinforcing association between needs frustration and OP for gaming. Although no indirect effect 
was found for time spent gaming, the results supported the hypothesized indirect effect of needs frustration. This is the first study to show evidence that a stronger OP for gaming may increase one's likelihood of experiencing greater daily needs frustration. It is possible that individuals' gaming pattern as well as their underlying motivation towards gaming somehow indirectly thwarts their experience of needs satisfaction in other domains outside of their engagement in video games. For instance, OP for gaming may contribute to an increased disengagement in environments that are unrelated to gaming, which further contributes to a susceptibility of experiencing greater needs frustration (e.g., feeling left or excluded out; feeling somewhat forced to behave a certain way). Utz, Jonas, and Tonkens (2012) found OP for gaming was associated with less offline friends and poorer offline friendship quality implying high-OP for gaming might decrease the possibility of satisfying relatedness needs outside the gaming environment. At present, it remains unclear whether OP for gaming contributed to a loss of friendships or whether the lack of friendships contributed to individuals' OP for gaming. However, based on the present findings, it is likely the lack of friendships and OP for gaming are bidirectionally related.

Other research on has revealed OP individuals ruminate more often and for longer periods of time than HP individuals implying a level of disengagement in non-passion domains (St-Louis, Carbonneau, \& Vallerand, 2016; Donahue et al., 2012; Ratelle, Vallerand, Mageau, Rousseau, \& Provencher, 2004). However, disengagement by itself does not actively obstruct individuals from satisfying their basic needs and thus is not sufficient evidence of needs frustration (Chen et al., 2015). Therefore, strong OP for gaming must provoke an active avoidance of non-gaming environments (e.g., school, work, interpersonal relationships) as well as potentially a change in how individuals engage in non-passion environments (e.g., acting more 
This is the peer reviewed version of the following article: [Mills, D.J., Milyavskaya, M., Mettler, J., Heath, N.L., and Derevensky, J.L. (2018). How do passion for video games and needs frustration explain time spent gaming? British Journal of Social Psychology, 57(2), 461-481. doi:10.1111/bjso.12239.

withdrawn).

As this is the first study to demonstrate this association within the area of video games, it is only possible to compare the present findings to those from a tangentially related area of study on the role of strong beliefs or internal pressures (e.g., perfectionism). Prior work in this area has found perfectionism to positively contribute to the experience of needs frustration (Boone, Vansteenkiste, Soenens, Van der Kaap-Deeder, \& Verstuyf, 2014; Costa, Coppolino, \& Oliva, 2016). It is possible that $\mathrm{OP}$ is a behavioural representation of similarly strong internal pressures to engage in one's passion. For instance, both OP and perfectionism have similar fears of failure that are rooted in a contingent self-worth (Frost, Marten, Lahart, \& Rosenblate, 1990; Vallerand, 2010). Nonetheless, future research is needed to address the mechanism that supports OP's role in contributing to the experience of needs frustration as it points towards a vicious cycle that must be interrupted in order for OP to possibly transition to HP.

Finally, findings from the first objective indicate that HP is negatively associated with reports of daily needs frustration, implying that HP may protect against the experience of needs frustration. Alternatively, perhaps HP video game users are better able to manage their gaming engagement compared to OP video game users to ensure their gaming does not conflict with other life domains. This was an unexpected finding in the present study. Furthermore, it was also inconsistent as HP at Baseline was not significantly associated with needs frustration at Wave 2 in the cross-lagged model. Therefore, it is too premature to make any substantial claims regarding HP's association with needs frustration, except that it highlights the contrast between the two types of passion proposed by DMP.

The present study is not without several limitations. First, self-report data assume all items were responded to honestly and interpreted correctly. Although minor issues were noted 
regarding items included in the needs frustration scale, the included items do align with the general definitions of competence, autonomy, and relatedness frustration as described by Vansteenkiste and Ryan (2013). Moreover, the high internal consistency and reliability of the measures included in the present study provide strong evidence that participants had generally interpreted each of the items accurately. Second, although a strength of the present study is the incorporation of multiple waves of data collection over a period of about 75 days, future research is needed to conduct a longitudinal study with greater lengths of time between data collections to account for changes in HP and OP for gaming. Within a similar vein, the present study is not experimental in nature, suggesting the need for future research to attempt to induce the perception of needs frustration or a type of passion. Third, the sampling of only university students limits the generalizability of these findings. Future research should attempt to recruit a more representative sample as well as explore these associations within the developmental period of adolescence. Fourth, as the present study did not seek to compare the relative contribution between low needs satisfaction and needs frustration to HP and OP for gaming, an assessment of daily needs satisfaction was not included. Thus, it is not possible to say the extent to which the daily frustration of basic needs adds to the understanding of gaming engagement beyond reports of needs satisfaction. Finally, it should be noted that the perception of needs satisfaction during gaming engagement was assumed versus assessed within the present study. Future research should include an assessment of needs satisfaction while gaming (c.f., Ryan, Rigby, et al., 2006) to ensure participants do in fact perceive at least some level of needs satisfaction through their gaming engagement. Moreover, within the context of the present findings, a moderated moderator is possible whereby reports of needs satisfaction while gaming moderate the effect reports of OP for gaming has on the relationship between needs frustration and time spent 
This is the peer reviewed version of the following article: [Mills, D.J., Milyavskaya, M., Mettler, J., Heath, N.L., and Derevensky, J.L. (2018). How do passion for video games and needs frustration explain time spent gaming? British Journal of Social Psychology, 57(2), 461-481. doi:10.1111/bjso.12239.

gaming (Hayes, 2013). Addition- ally, the present study only assessed time spent gaming as an outcome of either HP or OP for gaming. Future research may benefit from exploring whether HP and OP for gaming mediate or moderate the relation between needs frustration and maladaptive outcomes such as depressive symptoms of negative affect over time.

Notwithstanding the mentioned limitations of the present study, the reported findings offer original contributions regarding the unique relation between OP and needs frustration, and their role in explaining time spent gaming. Firstly, this is the only study to date showing the role of OP and gender in moderating the association between needs frustration and time spent gaming such that low-OP video game users and males report less time spent gaming when needs frustration rises. Secondly, needs frustration, and not time spent gaming, is predicted by and further reinforces an OP for gaming over time. It is likely that needs frustration plays an essential role in the development and further maintenance of an OP for gaming, and may be an underlying factor of Internet Gaming Disorder. 


\section{References}

American Psychiatric Association (2013). Diagnostic and statistical manual of mental disorders (5th ed.). Washington, DC: Author.

Bartholomew, K., Ntoumanis, N., Ryan, R., Bosch, J., \& Thøgersen-Ntoumani, C. (2011). Selfdetermination theory and diminished functioning: The role of interpersonal control and psychological need thwarting. Personality and Social Psychology Bulletin, 37, 14591473. https://doi.org/10.1177/0146167211413125

Bartholomew, K., Ntoumanis, N., Ryan, R., \& Thøgersen-Ntoumani, C. (2011). Psychological need thwarting in the sport context: Assessing the darker side of athletic experience. Journal of Sport \& Exercise Psychology, 33(1), 75-102. Retrieved from http://eprints.bham.ac.uk/602/. https://doi.org/10.1123/jsep.33.1.75

Bollen, K. A. (1989). Structural equations with latent variables. New York: John Wiley \& Sons Inc. https://doi.org/10.1002/9781118619179

Boone, L., Vansteenkiste, M., Soenens, B., Van der Kaap-Deeder, J., \& Verstuyf, J. (2014). Selfcritical perfectionism and binge eating symptoms: A longitudinal test of the intervening role of psychological need frustration. Journal of Counseling Psychology, 61, 363-373. https://doi. org/10.1037/a0036418

Bureau, J. S., Vallerand, R. J., Ntoumanis, N., \& Lafreni'ere, M.-A. K. (2012). On passion and Moral behavior in achievement settings: The mediating role of pride. Motivation and Emotion, 37(1), 121-133. https://doi.org/10.1007/s11031-012-9292-7 
This is the peer reviewed version of the following article: [Mills, D.J., Milyavskaya, M., Mettler, J., Heath, N.L., and Derevensky, J.L. (2018). How do passion for video games and needs frustration explain time spent gaming? British Journal of Social Psychology, 57(2), 461-481. doi:10.1111/bjso.12239.

Byrne, B. (2013). Structural equation modeling with AMOS: Basic concepts, applications, and programming. Mahwah, NJ: Routledge.

Carbonneau, N., Vallerand, R. J., Fernet, C., \& Guay, F. (2008). The role of passion for teaching in intrapersonal and interpersonal outcomes. Journal of Educational Psychology, 100, 977-987. https://doi.org/10.1037/a0012545

Chen, B., Vansteenkiste, M., Beyers, W., Boone, L., Deci, E. L., Van der Kaap-Deeder, J., ... Verstuyf, J. (2015). Basic psychological need satisfaction, need frustration, and need strength across four cultures. Motivation and Emotion, 39(2), 216-236. https://doi.org/10.1007/s11031-014-9450-1 Cohen, J. (1988). Statistical power analysis for the behavioral sciences (2nd ed.). Hillside, NJ: Erlbaum.

Cole, D. A., \& Maxwell, S. E. (2003). Testing mediational models with longitudinal data: questions and tips in the use of structural equation modeling. Journal of Abnormal Psychology, 112, 558- 577. https://doi.org/10.1037/0021-843X.112.4.558

Costa, S., Coppolino, P., \& Oliva, P. (2016). Exercise dependence and maladaptive perfectionism: The mediating role of basic psychological needs. International Journal of Mental Health and Addiction, 14(3), 241-256. https://doi.org/10.1007/s11469-015-9586$\underline{6}$

Costa, S., Ntoumanis, N., \& Bartholomew, K. J. (2015). Predicting the brighter and darker sides of interpersonal relationships: Does psychological need thwarting matter? Motivation and Emotion, 39(1), 11-24. https://doi.org/10.1007/s11031-014-9427-0

Curran, T., Hill, A. P., Appleton, P. R., Vallerand, R. J., \& Standage, M. (2015). The psychology of passion: A meta-analytical review of a decade of research on intrapersonal outcomes. Motivation and Emotion, 39, 631-655. https://doi.org/10.1007/s11031-015-9503-0 
Deci, E. L., \& Ryan, R. M. (2000). The "What" and "Why" of goal pursuits: Human needs and the self- determination of behavior. Psychological Inquiry, 11(4), 227-268. https://doi.org/10.1207/ S15327965PLI1104_01

Donahue, E. G., Forest, J., Vallerand, R. J., Lemyre, P.-N., Crevier-Braud, L., \& Bergeron, E'. (2012).

Passion for work and emotional exhaustion: The mediating role of rumination and recovery. Applied Psychology: Health and Well-Being, 4, 341-368. https://doi.org/10.1111/j.1758-0854. 2012.01078.x

Donahue, E. G., Rip, B., \& Vallerand, R. J. (2009). When winning is everything: On passion, identity, and aggression in sport. Psychology of Sport and Exercise, 10, 526-534. https://doi.org/10. 1016/j.psychsport.2009.02.002

Frost, R. O., Marten, P., Lahart, C., \& Rosenblate, R. (1990). The dimensions of perfectionism. Cognitive Therapy and Research, 14, 449-468. https://doi.org/10.1007/BF01172967

Fuster, H., Oberst, U., Griffiths, M., Carbonell, X., Chamarro, A., \& Talarn, A. (2012). Psychological motivation in online role-playing games: A study of Spanish World of Warcraft players. Anales de Psicologia, 28(1), 274-280. Retrieved from http://revistas.um.es/analesps/article/view/ 140752/0.

Griffiths, M., van Rooij, A. J., Kardefelt-Winther, D., Starcevic, V., Kir'aly, O., Pallesen, S., ... Demetrovics, Z. (2016). Working towards an international consensus on criteria for assessing internet gaming disorder: A critical commentary on Petry et al. (2014). Addiction, 111(1), 167- 175. https://doi.org/10.1111/add.13057

Gunnell, K. E., Crocker, P. R. E., Wilson, P. M., Mack, D. E., \& Zumbo, B. D. (2013). Psychological need satisfaction and thwarting: A test of Basic Psychological Needs 
This is the peer reviewed version of the following article: [Mills, D.J., Milyavskaya, M., Mettler, J., Heath, N.L., and Derevensky, J.L. (2018). How do passion for video games and needs frustration explain time spent gaming? British Journal of Social Psychology, 57(2), 461-481. doi:10.1111/bjso.12239.

Theory in physical activity contexts. Psychology of Sport and Exercise, 14(5), 599-607. https://doi.org/10.1016/j.psyc hsport.2013.03.007

Hayes, A. F. (2013). Introduction to mediation, moderation, and conditional process analysis. New York, NY: Guilford Press.

Houlfort, N., Fernet, C., Vallerand, R. J., Laframboise, A., Guay, F., \& Koestner, R. (2015). The role of passion for work and need satisfaction in psychological adjustment to retirement. Journal of Vocational Behavior, 88, 84-94. https://doi.org/10.1016/j.jvb.2015.02.005

Hu, L., \& Bentler, P. M. (1999). Cutoff criteria for fit indexes in covariance structure analysis: Conventional criteria versus new alternatives. Structural Equation Modeling: A Multidisciplinary Journal, 6(1), 1-55. https://doi.org/10.1080/10705519909540118

Johnson, D., Gardner, J., \& Sweetser, P. (2016). Motivations for videogame play: Predictors of time spent playing. Computers in Human Behavior, 63, 805-812. https://doi.org/10.1016/j.chb. 2016.06.028

King, D. L., Haagsma, M. C., Delfabbro, P. H., Gradisar, M., \& Griffiths, M. (2013). Toward a consensus definition of pathological video-gaming: A systematic review of psychometric assessment tools. Clinical Psychology Review, 33, 331-342. https://doi.org/10.1016/j.cpr. 2013.01.002

Kline, R. B. (2016). Principles and practice of structural equation modeling (4th ed.) New York: The Guilford Press.

Lafreni'ere, M.-A. K., Vallerand, R. J., Donahue, E. G., \& Lavigne, G. (2009). On the costs and benefits of gaming: The role of passion. Cyberpsychology \& Behavior, 12, 285-290. https://doi.org/10. 1089/cpb.2008.0234

Lafreni'ere, M.-A. K., Vallerand, R., \& Sedikides, C. (2013). On the relation between self- 
Enhancement and life satisfaction: The moderating role of passion. Self and Identity, 12, 597-609. https://doi. org/10.1080/15298868.2012.713558

Lalande, D., Vallerand, R. J., Lafreni'ere, M.-A. K., Verner-Filion, J., Laurent, F.-A., Forest, J., \& Paquet, Y. (2017). Obsessive passion: A compensatory response to unsatisfied needs. Journal of Personality, 85(2), 163-178. https://doi.org/10.1111/jopy.12229

Lemmens, J. S., Valkenburg, P. M., \& Gentile, D. A. (2015). The internet gaming disorder scale. Psychological Assessment, 27, 567-582. https://doi.org/10.1037/pas0000062

Little, R. J. A. (1988). A test of missing completely at random for multivariate data with missing values. Journal of the American Statistical Association, 83, 1198-1202. https://doi.org/10. 1093/biomet/86.1.1

Liu, M., \& Peng, W. (2009). Cognitive and psychological predictors of the negative outcomes associated with playing MMOGs (massively multiplayer online games). Computers in Human Behavior, 25, 1306-1311. https://doi.org/10.1016/j.chb.2009.06.002

Luth, M. T., Flinchbaugh, C. L., \& Ross, J. (2017). On the bike and in the cubicle: The role of passion and regulatory focus in cycling and work satisfaction. Psychology of Sport and Exercise, 28, 37-45. https://doi.org/10.1016/j.psychsport.2016.10.003

Mageau, G., Vallerand, R., Charest, J., Salvy, S.-J., Lacaille, N., Bouffard, T., \& Koestner, R. (2009). On the development of harmonious and obsessive passion: The role of autonomy support, activity specialization, and identification with the activity. Journal of Personality, 77, 601-646. https://doi.org/10.1111/j.1467-6494.2009.00559.x

Mills, D. J., Milyavskaya, M., Derevensky, J., \& Heath, N. L. (in press). Understanding the link between gaming motivation, needs frustration, and problematic gaming. European Journal of Social Psychology. Online advance publication. 
This is the peer reviewed version of the following article: [Mills, D.J., Milyavskaya, M., Mettler, J., Heath, N.L., and Derevensky, J.L. (2018). How do passion for video games and needs frustration explain time spent gaming? British Journal of Social Psychology, 57(2), 461-481. doi:10.1111/bjso.12239.

https://doi.org/10.1002/ejsp.2343

Mills, D. J., Milyavskaya, M., Mettler, J., \& Heath, N. L. (2017). Need satisfaction versus need frustration: An investigation into internet gaming disorder. Unpublished Manuscript.

Muth'en, L. K., \& Muth'en, B. O. (2015). Mplus user's guide (7th ed.). Los Angeles, CA: Author.

Peng, W., Lin, J.-H., Pfeiffer, K. A., \& Winn, B. (2012). Need satisfaction supportive game features as motivational determinants: An experimental study of a Self-Determination Theory guided exergame. Media Psychology, 15(2), 175-196. https://doi.org/10.1080/15213269.2012.673850

Preacher, K. J., Curran, P. J., \& Bauer, D. J. (2006). Computational tools for probing interactions in multiple linear regression, multilevel modeling, and latent curve analysis. Journal of Educational and Behavioral Statistics, 31(4), 437-448. https://doi.org/10.3102/10769986031004437

Przybylski, A. K., Weinstein, N., \& Murayama, K. (2017). Internet Gaming Disorder: Investigating the clinical relevance of a new phenomenon. American Journal of Psychiatry, 174, 230-236. https://doi.org/10.1176/appi.ajp.2016.16020224

Przybylski, A. K., Weinstein, N., Ryan, R., \& Rigby, C. S. (2009). Having to versus wanting to play: Background and consequences of harmonious versus obsessive engagement in video games. CyberPsychology \& Behavior, 12, 485-492. https://doi.org/10.1089/cpb.2009.0083

Ratelle, C. F., Carbonneau, N., Vallerand, R. J., \& Mageau, G. (2013). Passion in the romantic sphere: A look at relational outcomes. Motivation and Emotion, 37(1), 106-120. https://doi.org/10. 1007/s11031-012-9286-5 
Ratelle, C. F., Vallerand, R. J., Mageau, G. A., Rousseau, F. L., \& Provencher, P. (2004). When passion leads to problematic outcomes: A look at gambling. Journal of Gambling Studies, 20(2), 105- 119. https://doi.org/10.1023/B:JOGS.0000022304.96042.e6

Rehbein, F., Kleimann, M., \& Mo€ssle, T. (2010). Prevalence and risk factors of video game dependency in adolescence: results of a German nationwide survey. Cyberpsychology, Behavior and Social Networking, 13, 269-277. https://doi.org/10.1089/cyber.2009.0227

Reinecke, L. (2009). Games and recovery: The use of video and computer games to recuperate from stress and strain. Journal of Media Psychology, 21(3), 126-142. Retrieved from http://psycnet.a pa.orgjournals/jmp/21/3/126.

Reinecke, L., Tamborini, R., Grizzard, M., Lewis, R., Eden, A., \& David Bowman, N. (2012). Characterizing mood management as need satisfaction: The effects of intrinsic needs on selective exposure and mood repair. Journal of Communication, 62(3), 437-453. https://doi. org/10.1111/j.1460-2466.2012.01649.x

Ryan, R. M., \& Deci, E. L. (2000). Self-Determination Theory and the facilitation of intrinsic motivation, social development, and well-being. American Psychologist, 55(1), 68-78. https:// doi.org/10.1037/0003-066X.55.1.68

Ryan, R. M., \& Deci, E. L. (2017). Self-determination theory: basic psychological needs in motivation, development, and wellness. New York, NY: Guilford Press.

Ryan, R. M., Deci, E. L., Grolnick, W. S., \& La Guardia, J. G. (2006). The significance of autonomy and autonomy support in psychological development and psychopathology. In D. Cicchetti \& D. Cohen (Eds.), Developmental psychopathology, vol 1: theory and method (2nd ed., pp. 795- 849). New York, NY: Wiley. 
This is the peer reviewed version of the following article: [Mills, D.J., Milyavskaya, M., Mettler, J., Heath, N.L., and Derevensky, J.L. (2018). How do passion for video games and needs frustration explain time spent gaming? British Journal of Social Psychology, 57(2), 461-481. doi:10.1111/bjso.12239.

\section{https://doi.org/10.1177/0146167200264005}

Ryan, R. M., Deci, E. L., \& Vansteenkiste, M. (2016). Autonomy and autonomy disturbances in self- development and psychopathology: Research on motivation, attachment, and clinical process. In D. Cicchetti (Ed.), Developmental psychopathology: vol 1. theory and method (3rd ed., pp. 385-438). Hoboken, NJ: John Wiley \& Sons, Inc. https://doi.org/10.1002/9781119125556. devpsy109

Ryan, R. M., Rigby, C. S., \& Przybylski, A. K. (2006). The motivational pull of video games: A Self- Determination Theory approach. Motivation and Emotion, 30, 344-360. https://doi.org/10. 1007/s11031-006-9051-8

Shaw, A. (2012). Do you identify as a gamer? Gender, race, sexuality, and gamer identity. New Media \& Society, 14(1), 28-44. https://doi.org/10.1177/1461444811410394

Stenseng, F., \& Dalskau, L. H. (2010). Passion, self-esteem, and the role of comparative performance evaluation. Journal of Sport \& Exercise Psychology, 32, 881-894. https://doi.org/10.1123/jsep. 32.6.881

Stenseng, F., \& Phelps, J. (2013). Leisure and life satisfaction: The role of passion and life domain outcomes. World Leisure Journal, 55, 320-332. https://doi.org/10.1080/04419057.2013. 836558

St-Louis, A. C., Carbonneau, N., \& Vallerand, R. J. (2016). Passion for a cause: How it affects health and subjective well-being. Journal of Personality, 84(3), 263-276. https://doi.org/10.1111/ jopy.12157

Tamborini, R., Bowman, N. D., Eden, A., Grizzard, M., \& Organ, A. (2010). Defining media enjoyment as the satisfaction of intrinsic needs. Journal of Communication, 60, 758-777. https://doi.org/ 10.1111/j.1460-2466.2010.01513.x 
Utz, S., Jonas, K. J., \& Tonkens, E. (2012). Effects of passion for massively multiplayer online role- playing games on interpersonal relationships. Journal of Media Psychology, 24, 7786. https://doi.org/101027/18641105/a000066

Vallerand, R. J. (2010). On passion for life activities. Advances in Experimental Social Psychology, 42, 97-193. https://doi.org/10.1016/S0065-2601(10)42003-1

Vallerand, R. J. (2015). The psychology of passion. New York, NY: Oxford University Press, https:// doi.org/10.1093/acprof:oso/9780199777600.001.0001

Vallerand, R. J., Blanchard, C., Mageau, G., Koestner, R., Ratelle, C. F., Leonard, M., \& Gagne, M. (2003). Les passions de l'ame: On obsessive and harmonious passion. Journal of Personality and Social Psychology, 85, 756-767. https://doi.org/10.1037/0022-

\section{$\underline{3514.85 .4 .756}$}

Vallerand, R. J., Ntoumanis, N., Philippe, F. L., Lavigne, G. L., Carbonneau, N., Bonneville, A., .. . Maliha, G. (2008). On passion and sports fans: A look at football. Journal of Sports Sciences, 26, 1279-1293. https://doi.org/10.1080/02640410802123185

Vansteenkiste, M., \& Ryan, R. M. (2013). On psychological growth and vulnerability: Basic psychological need satisfaction and need frustration as a unifying principle. Journal of Psychotherapy Integration, 23, 263-280. https://doi.org/10.1037/a0032359

Wang, C.-C., \& Chu, Y.-S. (2007). Harmonious passion and obsessive passion in playing online games. Social Behavior and Personality, 35, 997-1006. https://doi.org/10.2224/sbp.2007.35. 7.997

Yee, N. (2006). The demographics, motivations, and derived experiences of users of massively multi- user online graphical environments. Presence: Teleoperators and Virtual Environments, 15, 309-329. https://doi.org/10.1162/pres.15.3.309 
This is the peer reviewed version of the following article: [Mills, D.J., Milyavskaya, M., Mettler, J., Heath, N.L., and Derevensky, J.L. (2018). How do passion for video games and needs frustration explain time spent gaming? British Journal of Social Psychology, 57(2), 461-481. doi:10.1111/bjso.12239.

\section{Tables and Figures}

\begin{tabular}{|c|c|c|c|}
\hline & $\frac{\text { Fall Cohort }}{n=349}$ & $\frac{\text { Winter Cohort }}{n=403}$ & $\begin{array}{l}\text { Statistical Comparisons } \\
\text { (Included vs Excluded Participants) }\end{array}$ \\
\hline Step 1 & $\begin{array}{c}\text { EXCLUDED } \\
\quad n=30 \\
\text { Incomplete questionnaire }\end{array}$ & $\begin{array}{c}\text { EXCLUDED } \\
\quad n=56 \\
\text { Incomplete questionnaire }\end{array}$ & Not enough data to assess differences \\
\hline Step 2 & $\begin{array}{c}\text { EXCLUDED } \\
\begin{array}{l}n=7 \\
\text { Participated in both cohorts }\end{array}\end{array}$ & $\begin{array}{c}\text { EXCLUDED } \\
n=7 \\
\text { Participated in both cohorts }\end{array}$ & No comparisons conducted \\
\hline Step 3 & $\begin{array}{c}\text { EXCLUDED } \\
n=103 \\
\text { No contact information } \\
\text { provided }\end{array}$ & $\begin{array}{c}\text { EXCLUDED } \\
n=118 \\
\text { No contact information } \\
\text { provided }\end{array}$ & $\begin{array}{l}\text { Neither gender }{ }^{\mathrm{a}} \text { nor age } \mathrm{e}^{\mathrm{b}} \text { were associated } \\
\text { with being included versus excluded in } \\
\text { the study within each cohort }\end{array}$ \\
\hline Step 4 & $\begin{array}{l}\text { EXCLUDED } \\
\qquad \begin{array}{l}n=45 \\
\text { Participated only at Baseline }\end{array}\end{array}$ & $\begin{array}{l}\text { EXCLUDED } \\
\quad n=54 \\
\text { Participated only at Baseline }\end{array}$ & $\begin{array}{l}\text { Neither gender }{ }^{\mathrm{c}} \text { nor age } \mathrm{e}^{\mathrm{d}} \text { were associated } \\
\text { with being included versus excluded in } \\
\text { the study within each cohort }\end{array}$ \\
\hline Step 5 & $\begin{array}{l}\text { EXCLUDED } \\
\quad n=18 \\
\text { Not presently enrolled } \\
\text { university }\end{array}$ & $\begin{array}{l}\text { EXCLUDED } \\
\quad n=24 \\
\text { Not presently enrolled } \\
\text { university }\end{array}$ & $\begin{array}{l}\text { Gender }^{\mathrm{e}} \text { was not associated with being } \\
\text { included versus excluded in the study } \\
\text { within each cohort, however, a higher age } \\
\text { was significantly associated with being } \\
\text { excluded from the study }\end{array}$ \\
\hline & $\begin{array}{c}\text { Final Sample } \\
n=147\end{array}$ & $\begin{array}{c}\text { Final Sample } \\
\quad n=143\end{array}$ & \\
\hline
\end{tabular}

Figure I. Graphical representation of the steps taken to select a final sample for the present study. ${ }^{\mathrm{a}}$ Gender-Fall Cohort: $\chi^{2}(\mathrm{I}, N=3 \mathrm{I} 3)=0.02, p=.88$; Winter Cohort: $\chi^{2}(\mathrm{I}, N=339)=\mathrm{I} .46, p=.23$. ${ }^{\mathrm{b}} \mathrm{Age}$ - Fall Cohort: $t(\mathrm{I} 66.75)=0.33, p=.74$; Winter Cohort: $t(\mathrm{II} 7.32)=0.82, p=.42 .{ }^{\mathrm{C}} \mathrm{Gender}-$ Fall Cohort: $\chi^{2}(I, N=2 I 0)=0.75, p=.48$; Winter Cohort: $\chi^{2}(I, N=22 I)=0.46, p=.6 I .{ }^{d}$ Age - Fall Cohort: $t(208)=0.00, p=.99 ;$ Winter Cohort: $t(219)=1.28, p=.20$. ${ }^{e}$ Gender - Fall Cohort: $\chi^{2}(\mathrm{I}, N=\mathrm{I65})=0.07, p=.80$; Winter Cohort: $\chi^{2}(\mathrm{I}, \mathrm{N}=\mathrm{I} 67)=0.0 \mathrm{I}, p=.92 .{ }^{\mathrm{f}}$ Age - Fall Cohort: $t$ $(I 7.26)=3.5 \mathrm{I}, p=.0 \mathrm{I}$; Winter Cohort: $t(23.23)=2.99, p=.0 \mathrm{I}$. 
Table I. Differences between cohorts at Baseline

\begin{tabular}{|c|c|c|c|c|c|}
\hline \multirow{3}{*}{$\begin{array}{l}\text { Gender } \\
\text { Graduate } \\
\text { programme }\end{array}$} & \multicolumn{2}{|c|}{$\begin{array}{l}\text { Fall Cohort } \\
(n=147)\end{array}$} & \multicolumn{2}{|c|}{$\begin{array}{l}\text { Winter Cohort } \\
\qquad(n=143)\end{array}$} & \multirow[t]{2}{*}{ Statistical comparison } \\
\hline & $52 \%$ male & $48 \%$ female & $64 \%$ male & $36 \%$ female & \\
\hline & $14 \%$ Yes & $86 \%$ No & $16 \%$ Yes & $84 \%$ No & $\chi^{2}(1, N=290)=0.182, p=.67$ \\
\hline $\begin{array}{l}\text { Age } \\
\text { (in years) }^{\mathrm{a}}\end{array}$ & $M=20.68$ & $S D=1.85$ & $M=21.40$ & $S D=2.60$ & $t(256.53)=2.7 \mathrm{I}, p=.0 \mathrm{I}$ \\
\hline $\begin{array}{l}\text { Time } \\
\text { Gaming } \\
\text { (in hours) }\end{array}$ & $M=8.6 I$ & $S D=8.83$ & $M=12.73$ & $S D=11.36$ & $t(284)=3.44, p=.01$ \\
\hline $\begin{array}{l}\text { Needs } \\
\text { Frustration }^{\mathrm{b}}\end{array}$ & $M=2.39$ & $S D=0.98$ & $M=2.34$ & $S D=1.09$ & $t(283)=0.40, p=.69$ \\
\hline $\begin{array}{l}\text { Harmonious } \\
\text { Passion }{ }^{c}\end{array}$ & $M=4.08$ & $S D=1.38$ & $M=4.31$ & $S D=1.21$ & $t(285)=1.53, p=.13$ \\
\hline $\begin{array}{l}\text { Obsessive } \\
\text { Passion }\end{array}$ & $M=1.94$ & $S D=0.97$ & $M=2.25$ & $S D=1.15$ & $t(274.83)=2.46, p=.02$ \\
\hline
\end{tabular}

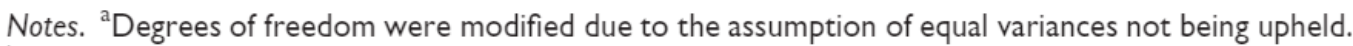

${ }^{b} n($ Fall Cohort $)=143 ; n($ Winter Cohort $)=142$.

${ }^{c} n$ (Fall Cohort $)=146 ; n($ Winter Cohort $)=|4|$.

${ }^{d} n($ Fall Cohort $)=145 ; n($ Winter Cohort $)=142$.

Table 2. Differences between those enrolled in graduate versus undergraduate programmes at Baseline

\begin{tabular}{llrlll}
\hline & \multicolumn{2}{c}{ Graduate $(n=44)$} & \multicolumn{1}{c}{ Undergraduate $(n=246)$} & \multicolumn{1}{c}{ Statistical comparisons } \\
\hline Gender & $64 \%$ male & $36 \%$ female & $57 \%$ male & $43 \%$ female & $\chi^{2}(I, N=290)=0.69, p=.4 \mathrm{I}$ \\
Age (in years) & $M=23.25$ & $S D=2.26$ & $M=20.64$ & $S D=2.04$ & $t(288)=7.69, p<.001$ \\
$\begin{array}{c}\text { Time Gaming } \\
\text { (in hours) }\end{array}$ & $M=11.55$ & $S D=14.62$ & $M=10.48$ & $S D=9.43$ & $t(284)=0.62, p=.54$ \\
$\begin{array}{c}\text { Needs } \\
\begin{array}{c}\text { Frustration } \\
\text { a }\end{array}\end{array}$ & $M=2.32$ & $S D=1.01$ & $M=2.37$ & $S D=1.04$ & $t(283)=0.32, p=.75$ \\
$\begin{array}{c}\text { Harmonious } \\
\text { Passion }\end{array}$ & $M=4.09$ & $S D=1.45$ & $M=4.21$ & $S D=1.28$ & $t(285)=0.56, p=.58$ \\
$\begin{array}{c}\text { Obsessive } \\
\text { Passion }\end{array}$ & $M=2.33$ & $S D=1.36$ & $M=2.05$ & $S D=1.01$ & $t(50.5 I)=1.25, p=.22$ \\
\hline
\end{tabular}

Notes. ${ }^{a} n($ Graduate $)=43 ; n($ Undergraduate $)=242$.

${ }^{b} n($ Graduate $)=43 ; n($ Undergraduate $)=244$.

${ }^{c} n($ Graduate $)=43 ; n($ Undergraduate $)=244$. 
This is the peer reviewed version of the following article: [Mills, D.J., Milyavskaya, M., Mettler, J., Heath, N.L., and Derevensky, J.L. (2018). How do passion for video games and needs frustration explain time spent gaming? British Journal of Social Psychology, 57(2), 461-481. doi:10.1111/bjso.12239.

Table 3. Correlations, Internal Consistencies, and Means

\begin{tabular}{|c|c|c|c|c|c|c|c|c|c|c|c|c|c|c|c|c|c|}
\hline & I & 2 & 3 & 4 & 5 & 6 & 7 & 8 & 9 & 10 & 11 & 12 & 13 & 14 & 15 & 16 & 17 \\
\hline I. Gender ${ }^{\mathrm{a}}$ & - & & & & & & & & & & & & & & & & \\
\hline 2. HP (Baseline) & -0.19 & .82 & & & & & & & & & & & & & & & \\
\hline 3. OP (Baseline) & $-0.22 *$ & $0.26 *$ & .85 & & & & & & & & & & & & & & \\
\hline 4. TG (Baseline) & $-0.21 *$ & $0.28^{*}$ & $0.46^{*}$ & - & & & & & & & & & & & & & \\
\hline 5. TG (Wave I) & $-0.25 *$ & $0.24 *$ & $0.39 *$ & $0.70^{*}$ & - & & & & & & & & & & & & \\
\hline 6. TG (Wave 2) & $-0.24 *$ & $0.26^{*}$ & $0.4 I^{*}$ & $0.74^{*}$ & $0.84 *$ & - & & & & & & & & & & & \\
\hline 7. TG (Wave 3) & $-0.3 I^{*}$ & $0.20^{*}$ & $0.4 I^{*}$ & $0.67 *$ & $0.66^{*}$ & $0.7 I^{*}$ & - & & & & & & & & & & \\
\hline 8. TG (Wave 4) & $-0.27^{*}$ & 0.16 & $0.38^{*}$ & $0.66 *$ & $0.67 *$ & $0.81 *$ & $0.69 *$ & - & & & & & & & & & \\
\hline 9. TG (Final) & $-0.32^{*}$ & $0.22 *$ & $0.38^{*}$ & $0.58^{*}$ & $0.71 *$ & $0.78^{*}$ & $0.72^{*}$ & $0.79 *$ & - & & & & & & & & \\
\hline 10. NF (Baseline) & 0.11 & -0.11 & $0.24 *$ & -0.04 & -0.07 & -0.06 & -0.06 & -0.02 & -0.04 & .92 & & & & & & & \\
\hline I I. NF (Wave I) & 0.19 & -0.14 & $0.22 *$ & -0.01 & -0.03 & -0.02 & 0.03 & 0.02 & 0.04 & $0.68^{*}$ & .91 & & & & & & \\
\hline 12. NF (Wave 2) & 0.19 & -0.16 & $0.26 *$ & 0.01 & -0.02 & 0.00 & 0.02 & 0.02 & 0.06 & $0.63^{*}$ & $0.79 *$ & .92 & & & & & \\
\hline 13. NF (Wave 3) & $0.23 *$ & -0.11 & 0.15 & -0.06 & -0.08 & -0.07 & -0.02 & -0.05 & 0.01 & $0.59 *$ & $0.74 *$ & $0.84^{*}$ & .93 & & & & \\
\hline 14. NF (Wave 4) & 0.13 & -0.15 & 0.19 & -0.02 & -0.01 & 0.01 & 0.00 & 0.08 & 0.06 & $0.66 *$ & $0.80 *$ & $0.78 *$ & $0.78^{*}$ & .95 & & & \\
\hline 15. NF (Final) & 0.16 & -0.12 & 0.18 & -0.06 & -0.05 & -0.04 & -0.04 & -0.01 & 0.02 & $0.64 *$ & $0.72 *$ & $0.76 *$ & $0.77 *$ & $0.87 *$ & .94 & & \\
\hline 16. HP (Final) & -0.14 & $0.71^{*}$ & 0.13 & 0.20 & 0.16 & 0.19 & 0.16 & 0.12 & 0.14 & -0.16 & -0.18 & -0.18 & -0.20 & $-0.23 *$ & $-0.23 *$ & .84 & \\
\hline 17. OP (Final) & -0.20 & 0.15 & $0.61 *$ & $0.31 *$ & $0.27 *$ & $0.38 *$ & $0.36 *$ & $0.35 *$ & $0.44 *$ & 0.14 & $0.22 *$ & $0.30^{*}$ & $0.22 *$ & $0.24 *$ & $0.23^{*}$ & 0.14 & .86 \\
\hline Mean & - & 4.19 & 2.10 & 10.62 & 8.69 & 9.12 & 10.68 & 8.37 & 9.50 & 2.36 & 2.60 & 2.61 & 2.52 & 2.58 & 2.45 & 4.22 & 2.15 \\
\hline$S D$ & - & 1.30 & 1.07 & 10.30 & 8.49 & 8.78 & 10.13 & 8.71 & 8.88 & 1.03 & 0.87 & 0.88 & 0.89 & 0.94 & 0.92 & 1.09 & 0.92 \\
\hline
\end{tabular}

Notes. Cronbach alphas presented across diagonal in italics.

HP, Harmonious Passion; OP, Obsessive Passion; TG, Time Gaming (in hours); NF, Needs Frustration.

${ }^{a}$ male $=1 ;$ female $=2$.

$* p<.0004$ (Bonferroni correction). 


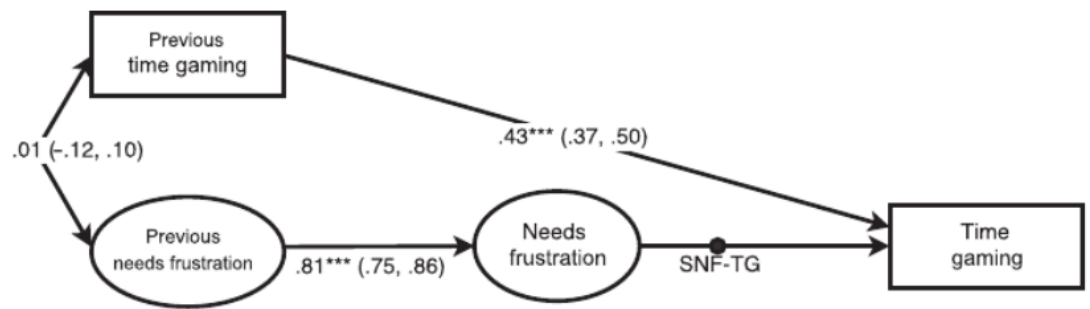

Within

Between

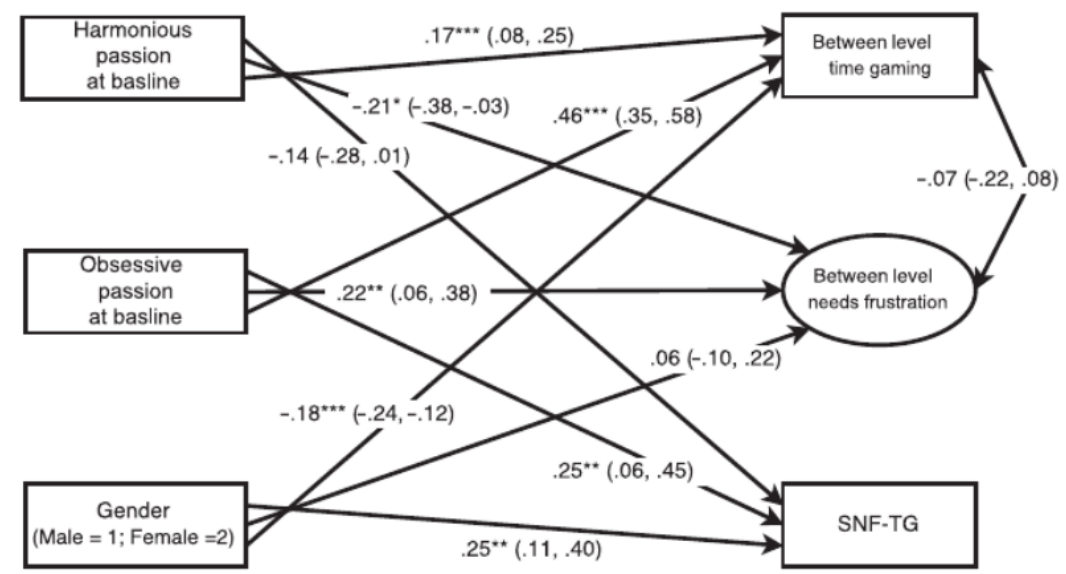

Figure 2. Results from the multilevel model analysis. All path coefficients are standardized with $95 \%$ confidence intervals included in the parentheses. SNF-TG - Slope of needs frustration and time spent gaming. $* p<.05, * * p<.01, * * * p<.001$. 
This is the peer reviewed version of the following article: [Mills, D.J., Milyavskaya, M., Mettler, J., Heath, N.L., and Derevensky, J.L. (2018). How do passion for video games and needs frustration explain time spent gaming? British Journal of Social Psychology, 57(2), 461-481. doi:10.1111/bjso.12239.

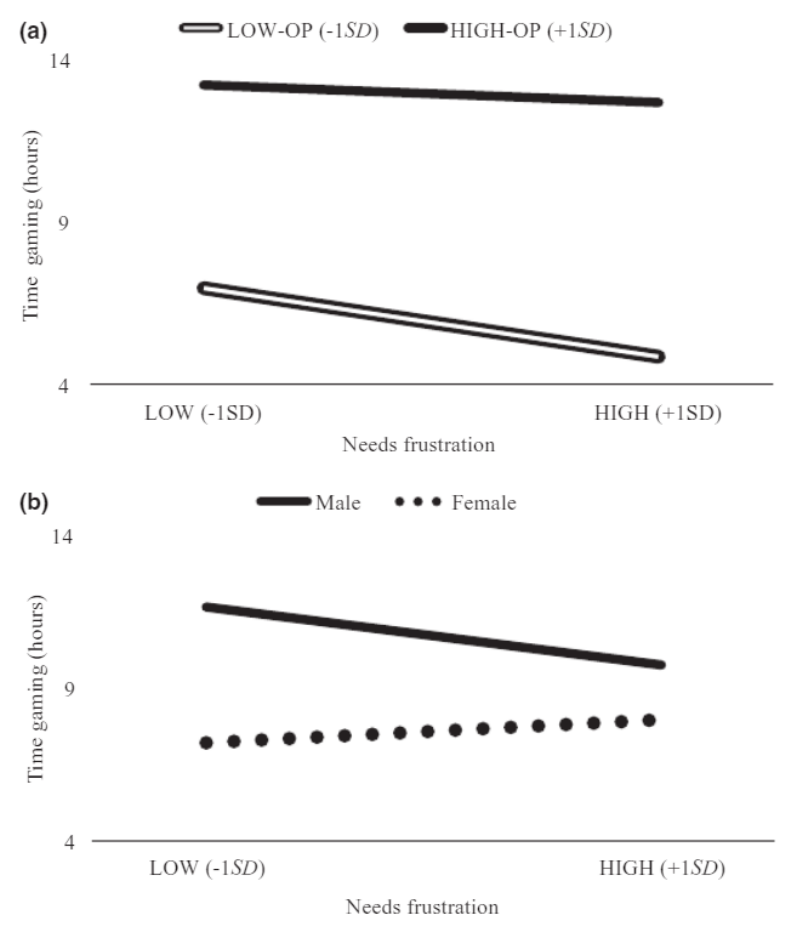

Figure 3. The moderational effect of (a) OP and (b) gender on the association between needs frustration and time gaming.

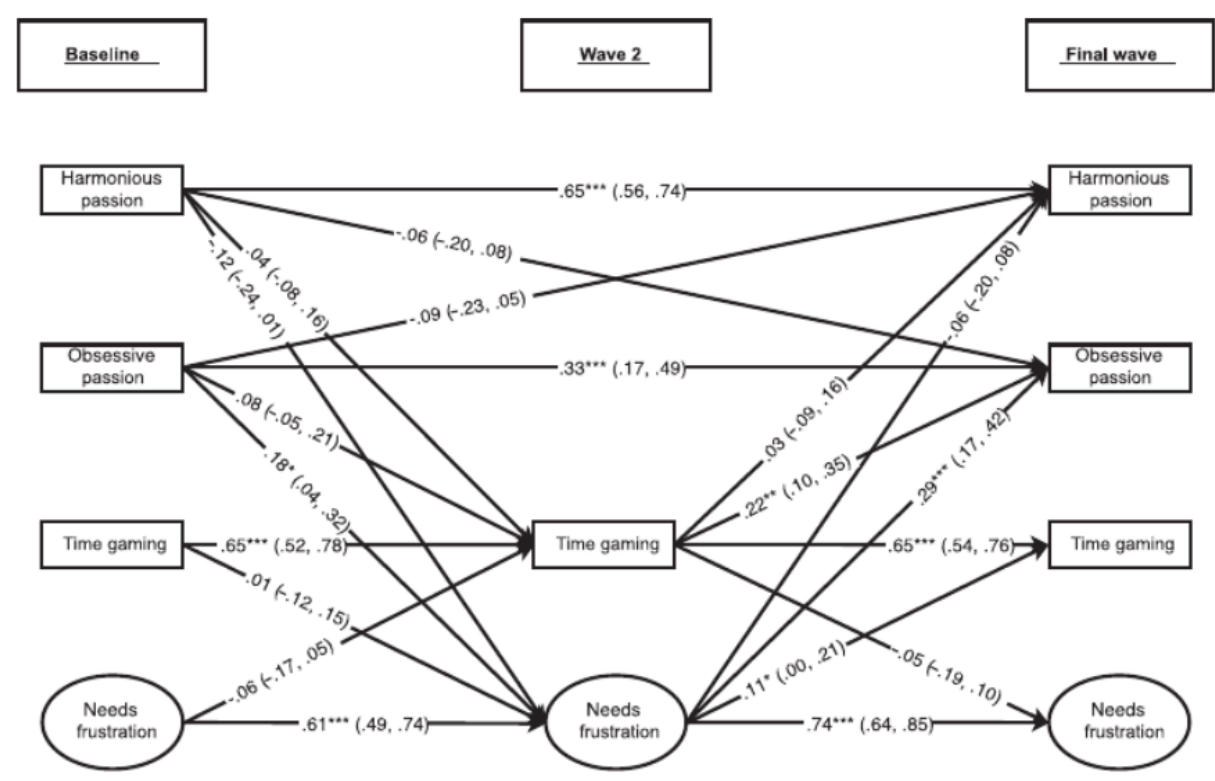

Figure 4. Results from the cross-lagged analysis. All path coefficients are standardized with $95 \%$ confidence intervals included in the parentheses. ${ }^{*} p<.05,{ }^{*} p<.01$, $* * * p<.001$. 